\title{
SOLID MISCIBILITY OF COMMON-ANION LITHIUM AND SODIUM HALIDES. EXPERIMENTAL DETERMINATION OF THE REGION OF DEMIXING IN LITHIUM BROMIDE + SODIUM BROMIDE
}

\author{
D. DOORNHOF, H.J. VAN WIJK and H.A.J. OONK
}

General Chemistry Laboratory, Chemical Thermodynamics Group, University of Utrecht, Utrecht (The Netherlands)

(Received 6 December 1983)

\section{ABSTRACT}

The region of demixing of solid lithium bromide + sodium bromide mixtures has been measured by X-ray diffraction. The critical temperature of mixing corresponding to a thermodynamic fit of the experimental data is $513 \mathrm{~K}$. Estimates are given of the regions of demixing in solid lithium chloride + sodium chloride and solid lithium iodide + sodium iodide.

\section{INTRODUCTION}

Data in the literature on the solid miscibility of lithium and sodium halides are not only scarce, but, as far as the chloride and bromide systems are concerned, they are also contradictory. Before going into detail it is worthwhile examining what phenomena can be expected a priori on the basis of general observations regarding solid miscibility and compound formation.

As for the miscibility, Lumsden [1] has shown that complete sub-solidus miscibility is to be expected when the ratio of the interionic distances of the pure alkali halide components is between 1.00 and about 1.12. According to this view complete sub-solidus miscibility is to be expected for $(\mathrm{Li}, \mathrm{Na}) \mathrm{I},(\mathrm{Li}$, $\mathrm{Na}) \mathrm{Br}$ and $(\mathrm{Li}, \mathrm{Na}) \mathrm{Cl}$.

As for compound formation, Gromakov and Gromakova [2] deduced some general regularities from phase diagrams, reported in the literature, for common-chloride and common-bromide alkali halide systems. In view of this, compounds of lithium and sodium halides are not expected to form.

\section{The LiF + NaF system}

The ( $\mathrm{Li}, \mathrm{Na}) \mathrm{F}$ system, for which the (room temperature) ratio of the interionic distances is 1.124 , is a system with limited solid miscibility at the 
eutectic temperature. The evidence from phase-diagram data given by Holm [3] and by Matiasovsky et al. [4] is supported by the results of interdiffusion experiments reported by Short and Roy [5]; see also ref. 6 .

\section{The $\mathrm{LiCl}+\mathrm{NaCl}$ system}

According to Zhemchuzhnyi and Rambakh [7], who performed coolingcurve experiments, there is complete sub-solidus miscibility. The existence of a region of demixing (ROD) in the solid state, having a critical temperature of about $313^{\circ} \mathrm{C}$, was derived from small additional arrests in the cooling curves. Formation of the incongruently melting compound $\mathrm{LiCl} \cdot \mathrm{NaCl}$ was reported by Akopov and Bergman [8], and the formation of another compound $\mathrm{LiCl} \cdot 2 \mathrm{NaCl}$ was reported by Arabadzhan and Bergman [9] and also by Akopov and Korobka [10]. Storonkin et al. [11], who combined thermal analysis with X-ray methods could not detect the formation of compounds. Compound formation had also already been ruled out by Smits et al. [12], who employed X-ray analysis and calorimetric and solubility experiments.

The $\mathrm{LiBr}+\mathrm{NaBr}$ system

According to Kellner [13] there is complete sub-solidus miscibility. Arabadzhan and Bergman [9] reported the formation of two compounds with probable formulae $\mathrm{LiBr} \cdot \mathrm{NaBr}$ and $\mathrm{LiBr} \cdot 2 \mathrm{NaBr}$. Bugaenko et al. [14] on the other hand, inferred from X-ray experiments the existence of complete sub-solidus miscibility and the absence of compound formation.

The LiI + NaI system

The existence of complete sub-solidus miscibility follows from the experiments of Ohno and Furukawa [15].

In this paper the results of $\mathrm{X}$-ray investigations and thermodynamic computations are presented.

The X-ray method was used to determine the region of demixing (ROD) in solid $(\mathrm{Li}, \mathrm{Na}) \mathrm{Br}$. Thermodynamic assessment of phase-diagram data was carried out on the solid-liquid phase diagrams reported in the literature for the systems $(\mathrm{Li}, \mathrm{Na}) \mathrm{Cl},(\mathrm{Li}, \mathrm{Na}) \mathrm{Br}$ and $(\mathrm{Li}, \mathrm{Na}) \mathrm{I}$ and in addition on the $\mathrm{ROD}$ in $(\mathrm{Li}, \mathrm{Na}) \mathrm{Br}$ reported here. The result of the thermodynamic assessment of the solid-liquid equilibrium of the system $(\mathrm{Li}, \mathrm{Na}) \mathrm{F}$ has already been published [6]. 


\section{EXPERIMENTAL}

The region of demixing in solid $\mathrm{LiBr}+\mathrm{NaBr}$

\section{Materials, sample preparation}

'The starting materials, $\mathrm{LiBr}$ and $\mathrm{NaBr}$ (Merck, >99\%), were dried and stored at $180^{\circ} \mathrm{C}$ to prevent absorption of moisture from the atmosphere. Because of the hygroscopicity of $\mathrm{LiBr}$ most operations were carried out in a glove box under nitrogen atmosphere. Mechanical mixtures of $\mathrm{LiBr}$ and $\mathrm{NaBr}$, prepared by careful weighing, were melted in an evacuated capsule. Next, the fused mixtures were powdered in an agate mortar, after which the powder was transferred into capillaries $(0.3 \mathrm{~mm}$ ID). The latter were sealed by melting the ends. Five capillaries, $8-\mathrm{mm}$ long, were placed in a frame and introduced into the camera.

\section{$X$-ray measurements}

The X-ray measurements were carried out with a temperature-programmable Guinier camera using $\mathrm{Cu} K_{\alpha}$ radiation. The temperature was measured with a platinum/platinum- $10 \%$ rhodium thermocouple. The uncertainty in these measurements is about $2 \mathrm{~K}$. First, X-ray diffraction patterns were made of the pure salts in the range $350-600 \mathrm{~K}$. Second, from a preliminary experiment carried out on a $50 \%$ mixture it was found that at $600 \mathrm{~K}$ homogeneous solid mixtures were formed. Subsequently, the region of demixing was determined as follows. Samples with overall compositions varying from 30 to $60 \mathrm{~mol} \% \mathrm{NaBr}$ were placed in the camera and kept at $600 \mathrm{~K}$ for $20 \mathrm{~h}$. Thereafter, the temperature was lowered slowly to the selected temperature and diffraction patterns were made. After $8 \mathrm{~h}$ the patterns remained constant.

\section{RESULTS}

The lattice parameters of the pure salts, derived from the diffraction patterns, are given in Table 1 . The compositions of the coexisting solid phases as a function of temperature are given in Table 2. These compositions were derived from the diffraction patterns, assuming for the pure substances linear dependence of the lattice parameter on temperature, and for the mixtures at given temperature linear dependence of the lattice parameter on mole fraction. The uncertainties in the experimental region-of-demixing data are estimated as $\delta T=2 \mathrm{~K}$ and $\delta X^{\prime}=\delta Y^{\prime}=0.02$.

\section{Phase diagram analysis}

Phase-diagram data were assessed with the computer programs LIQFIT and EXTXD/SIVAMIN. A short description of these programs is given in 
TABLE 1

Values of the lattice constants $(\AA)$ of lithium and sodium bromide as a function of temperature

\begin{tabular}{lll}
\hline$T(\mathrm{~K})$ & $\mathrm{LiBr}$ & $\mathrm{NaBr}$ \\
\hline 295 & 5.492 & 5.972 \\
353 & 5.511 & 5.983 \\
392 & 5.525 & 5.994 \\
427 & 5.536 & 6.000 \\
474 & 5.546 & 6.012 \\
493 & 5.556 & 6.017 \\
576 & 5.580 & 6.037 \\
\hline
\end{tabular}

Table 3; for a detailed description and directions for use the reader is referred to earlier publications $[6,16,17]$. The text of LIQFIT, written in FORTRAN, can be found in ref. 18, whereas the region-of-demixing version of EXTXD is now available in PASCAL.

The region of demixing in $\mathrm{LiBr}+\mathrm{NaBr}$

From an "eye-fit" of the data points given in Table 2, 17 triplets (temperature; mole fraction of left-hand boundary; mole fraction of righthand boundary) were read from 333 to $493 \mathrm{~K}$ at $10-\mathrm{K}$ intervals. These 17 triplets were used as the input data set for the EXTXD calculations.

The EXTXD solution, the excess Gibbs energy function, with four adjusted constants is as follows

$$
\begin{aligned}
G^{\mathrm{E}}(T, X)= & X(1-X)\left\{\left(11772-6.4684 \frac{T}{\mathrm{~K}}\right)\right. \\
& \left.+\left(789-0.5166 \frac{T}{\mathrm{~K}}\right)(1-2 X)\right\} \mathrm{J} \mathrm{mol}^{-1}
\end{aligned}
$$

The region of demixing corresponding to this function is shown in Fig. 1.

\section{TABLE 2}

The region of demixing in solid lithium bromide + sodium bromide: Temperature; experimental mole fraction values of the boundaries; mole fractions calculated

\begin{tabular}{lllll}
\hline$T(\mathrm{~K})$ & $X_{\text {exp }}^{\prime}$ & $Y_{\text {exp }}^{\prime}$ & $X_{\text {calc }}$ & $Y_{\text {calc }}$ \\
\hline 353 & 0.05 & 0.95 & 0.041 & 0.934 \\
374 & 0.06 & 0.91 & 0.056 & 0.914 \\
394 & 0.07 & 0.89 & 0.073 & 0.890 \\
414 & 0.09 & 0.85 & 0.095 & 0.861 \\
428 & 0.10 & 0.84 & 0.113 & 0.838 \\
453 & 0.16 & 0.79 & 0.155 & 0.785 \\
473 & 0.21 & 0.73 & 0.202 & 0.729 \\
488 & 0.26 & & 0.249 & 0.674 \\
502 & & 0.61 & 0.316 & 0.600 \\
\hline
\end{tabular}




\section{TABLE 3}

Characteristics of the computer programs LIQFIT and EXTXD

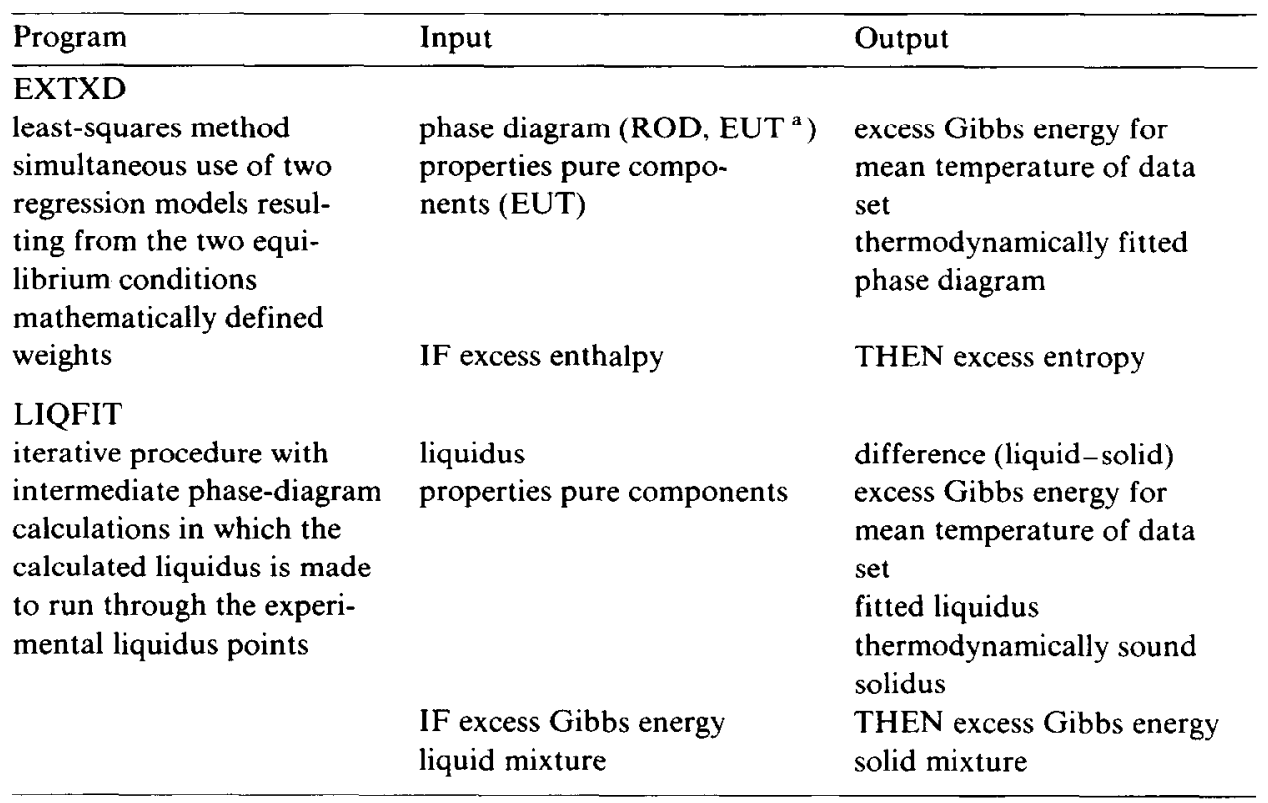

a $\mathrm{EUT}=$ eutectic system.

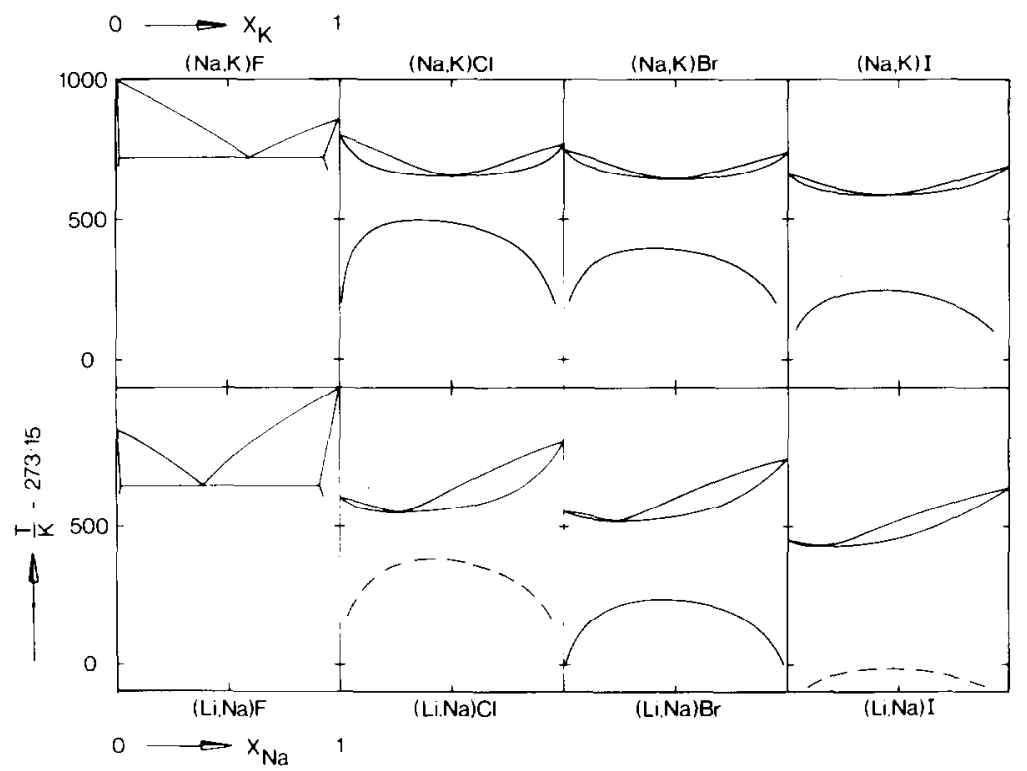

Fig. 1. The common-anion sodium halide + potassium halide and lithium halide + sodium halide systems: (_- $)$, assessed experimental phase diagram data; $\left(-._{--}\right)$, estimated boundary of region of demixing. 
The mole fractions of the boundaries calculated for the experimental temperatures are given in Table 2 . The critical point corresponding to this function has $T_{\mathrm{c}}=512.8 \mathrm{~K} ; X_{\mathrm{c}}=0.455$. Equation (1) has a mathematical and a physical meaning. The mathematical meaning is that it includes an accurate representation of the region of demixing. Its physical meaning is that it gives the excess Gibbs energy of the mixture for the weighted mean temperature of the data set

$G^{\mathrm{E}}(440 \mathrm{~K}, X)=X(1-X)\{8.93+0.56(1-2 X)\} \mathrm{kJ} \mathrm{mol}^{-1}$

\section{The solid-liquid equilibria}

The solid-liquid equilibria of the systems $(\mathrm{Li}, \mathrm{Na}) \mathrm{Cl},(\mathrm{Li}, \mathrm{Na}) \mathrm{Br}$ and $(\mathrm{Li}$, $\mathrm{Na}$ I were analyzed using the LIQFIT method.

The liquidus points necessary as input for the calculations were points read from eye-fits of the experimental liquidus data. The data set used for $(\mathrm{Li}, \mathrm{Na}) \mathrm{Cl}$ was that of Akopov and Korobka [10], that for $(\mathrm{Li}, \mathrm{Na}) \mathrm{Br}$ was from Kellner [13], and that for ( $\mathrm{Li}, \mathrm{Na}) \mathrm{I}$ was from Ohno and Furukawa [15]. For the entropies of melting of the pure substances we used the values given by Dworkin and Bredig [19].

LIQFIT calculations yield the excess Gibbs energy difference function (liquid minus solid) for the mean temperature of the solid-liquid region, or in other words the coefficients $\Delta G_{\mathrm{i}}$ of

$\Delta G^{\mathrm{E}}=G_{(1)}^{\mathrm{E}}-G_{(\mathrm{s})}^{\mathrm{E}}=X(1-X)\left\{\Delta G_{1}+\Delta G_{2}(1-2 X)+\Delta G_{3}(1-2 X)^{2}+\ldots\right\}$

The calculated $\Delta G_{\mathrm{i}}$ values are given in Table 4 . The assessed phase diagrams are shown in Fig. 1.

\section{DISCUSSION}

The experimental results obtained for the system $(\mathrm{Li}, \mathrm{Na}) \mathrm{Br}$ are in agreement with the a priori expectations mentioned in the introduction. The

\section{TABLE 4}

Mean temperature of solid-liquid regions and coefficients of the excess Gibbs energy difference function $\left(\mathrm{kJ} \mathrm{mol}^{-1}\right)$, obtained by LIQFIT

\begin{tabular}{lllll} 
System & $T(\mathrm{~K})$ & $\Delta G_{1}$ & $\Delta \bar{G}_{2}-\bar{\Delta}-\overline{G_{3}}-$ \\
\hline$(\mathrm{Li}, \mathrm{Na}) \mathrm{Cl}$ & 895 & -11.8 & -2.4 & \\
$(\mathrm{Li}, \mathrm{Na}) \mathrm{Br}$ & 840 & -8.7 & 2.8 & \\
$(\mathrm{Li}, \mathrm{Na}) \mathrm{I}$ & 735 & -6.4 & -2.9 & 0.9 \\
\hline
\end{tabular}


X-ray experiments support the absence of compounds and confirm the existence of a sub-solidus region of complete miscibility.

If we assume that compounds do not form in the systems $(\mathrm{Li}, \mathrm{Na}) \mathrm{Cl}$ and $(\mathrm{Li}, \mathrm{Na}) \mathrm{I}$ we can make estimates of the sub-solidus regions of the phase diagrams of these systems. The excess Gibbs energies, as a function of temperature and mole fraction, needed for the calculation of the regions of demixing, are not directly available. Estimates of these functions can be made indirectly by correlating the experimental information available for other common-anion alkali halide mixtures [20]. If the experimental heats of mixing are compared with the excess Gibbs energies derived from phase diagrams (and valid for the mean temperature of the heterogeneous-equilibrium region) it is found that the excess Gibbs energies of liquid as well as solid mixtures stand in a constant ratio to the heats of mixing. This suggests that for these systems the ratio between excess enthalpy and excess entropy is much the same. For the liquid common-anion mixtures the ratio is about $2.4 \mathrm{kK}$ whereas for the solid mixtures the ratio is about $3 \mathrm{kK}$. These considerations are illustrated in the regions of demixing calculated for ( $\mathrm{Li}$, $\mathrm{Na}) \mathrm{Cl}$ and ( $\mathrm{Li}, \mathrm{Na}) \mathrm{I}$ (Fig. 1, dashed lines).

The region of demixing calculated for $(\mathrm{Li}, \mathrm{Na}) \mathrm{I}$ is well below the solid-liquid region and leaves no doubt about the occurrence of a region of complete solid miscibility.

In the case of $(\mathrm{Li}, \mathrm{Na}) \mathrm{Cl}$ the calculated region of demixing is much closer to the solid-liquid region, so, in view of the uncertainties in the estimates, a decisive experiment is needed to confirm, or to rule out, the existence of a region of complete sub-solidus miscibility.

The evidence so far available implies that the lithium + sodium halide phase diagrams show the same characteristics as the corresponding sodium + potassium halide phase diagrams (see Fig. 1). The regions of demixing in the sodium-potassium systems are given by Chanh [21].

\section{RFFERENCES}

1 J. Lumsden, Thermodynamics of Molten Salt Mixtures, Academic Press, London, 1966.

2 S.D. Gromakov and L.M. Gromakova, Zh. Fiz. Khim., 27 (1953) 1545.

3 J.L. Holm, Acta Chem. Scand., 19 (1965) 638.

4 K. Matiasovsky, I. Cakajdova and M. Malinovsky, Chem. Zvesti, 19 (1965) 513.

5 J.M. Short and R. Roy, J. Am. Ceram. Soc., 47 (1964) 149.

6 H.A.J. Oonk, J.G. Blok and J.A. Bouwstra, Calphad, 7 (1983) 205.

7 S.F. Zhemchuzhnyi and F. Rambakh, Izv. S.-Petersburg Politekh. Inst., 12 (1909) 349.

8 E.K. Akopov and A.G. Bergnan, Zh. Neorg. Khim., 2 (1957) 383.

9 A.S. Arabadzhan and A.G. Bergman, Zh. Neorg. Khim., 7 (1962) 2226.

10 E.K. Akopov and E.I. Korobka, Ukr. Khim. Zh., 35 (1969) 588.

11 A.V. Storonkin, O.D. Grebenikova, I.V. Krivousova, I.I. Kozhina and I.V. Vasilkova, Vestn. Leningr. Univ., Fiz. Khim., 10 (1973) 70.

12 A. Smits, J. Elgersma and M.E. Hardenberg, Recl. Trav. Chim. Pays-Bas, 43 (1924) 671. 
13 G. Kellner, Z. Anorg. Chem., 99 (1917) 144.

14 V.V. Bugaenko, R.V. Chernov and Y.P. Krasan, Ukr. Khim. Zh., 43 (1977) 1215.

15 H. Ohno and K. Furukawa, J. Nucl. Mater., 64 (1977) 37.

16 H.A.J. Oonk, J.G. Blok, B. van de Koot and N. Brouwer, Calphad, 5 (1981) 55.

17 J.A. Bouwstra and H.A.J. Oonk, Calphad, 6 (1982) 11.

18 R. Moerkens, J.A. Bouwstra and H.A.J. Oonk, Calphad, 7 (1983) 213.

19 A.S. Dworkin and M.A. Bredig, J. Phys. Chem., 64 (1960) 269.

20 H.A.J. Oonk, J.A. Bouwstra and P. Eisinga, to be published.

21 N.B. Chanh, J. Chim. Phys., 61 (1964) 1428. 